Research Article

\title{
Numerical Analyses of Fracturing Behavior and Strength of Specimens with Two Parallel Infilled Flaws under Uniaxial Compression
}

\author{
Huilin Le $\left(\mathbb{D}\right.$, Jihong Wei $\mathbb{D}^{D}$, Shaorui Sun $(\mathbb{D}$, Wuchao Wang $(\mathbb{D}$, and Haotian Fan $(\mathbb{D})$ \\ Department of Geology Engineering, School of Earth Sciences and Engineering, Hohai University, Nanjing 210098, China \\ Correspondence should be addressed to Huilin Le; lehuilin@hhu.edu.cn
}

Received 19 October 2020; Revised 25 November 2020; Accepted 27 January 2021; Published 13 February 2021

Academic Editor: Manchao He

Copyright (c) 2021 Huilin Le et al. This is an open access article distributed under the Creative Commons Attribution License, which permits unrestricted use, distribution, and reproduction in any medium, provided the original work is properly cited.

\begin{abstract}
Grouting is a common method used to fill rock joints to improve the stability and integrity of rock mass in geotechnical engineering, and the filling has been observed to have an effect on crack behavior and mechanical property. To investigate this topic, a numerical study of crack behavior and mechanical property of rock samples with two parallel open flaws or infilled flaws under uniaxial compression was conducted in this research. The smooth joint model was proved to be suitable to simulate the interface between rock material and grout material. The occurrence of shear cracks at the interface between rock material and grout material as well as the occurrence of tensile cracks in the grouting material has been successfully simulated in this research. Numerical results indicate that grouting can reduce the tensile force near the flaws, suppress the generation of tensile cracks, and improve the initiation stress of the sample. The tensile force in the specimens with infilled flaws is smaller than that with open flaws, which lead to the improvement of the peak strength of the sample. Moreover, crack development and mechanical properties of samples are affected by bridge inclination angle and flaw inclination angle.
\end{abstract}

\section{Introduction}

Under the action of geological movement and excavation disturbance, a large number of flaws are produced in rock masses, which often contain infillings. Grouting, as the main method of strengthening fractured rock mass, has the characteristics of improving the strength and reducing the deformation of the rock mass. Therefore, fractures in the rock mass can be manually infilled by grouting material. Mechanical property and crack behavior of fractured rock masses may be affected by infilling materials. Although extensive research focused on fracturing behavior and mechanical property of rock masses with open flaws [1-7], the study on the mechanical behavior of rock masses with grouting fracture is insufficient.

Some researchers conducted studies about the fracturing behavior of rock specimens with closed flaws. Bobet and Einstein [8] carried out experimental tests on gypsum specimens containing open or closed flaws and found that partial debonding and slippage of the closed flaws were requisites for the emanation of a new crack. A detailed comparison of crack coalescence in samples containing open and closed flaws was made by Park and Bobet [9]; they pointed out that the main difference was that the initiation stress as well as the coalescence stress for open flaws is lower than that for closed flaws. The reason for this phenomenon is that closed flaws can transfer normal stress and the friction along the closed flaws improves the ability to sustain the shear stress. Therefore, cracks are hard to initiate from the tip of closed flaws than from the tips of open flaws. Huang et al. [10] conducted triaxial compressive tests on sandstone specimens containing two closed flaws to study mechanical behaviors and found that the influence of the arrangement of the flaw pair on the rock deformation, peak stress, and crack behavior is greater than the confining pressure. Duriez et al. [11] used an innovative micromechanical method to analyze the damage mechanism occurring during open and closed flaws propagation. They found that the mechanical and geometrical characteristics of the initial flaw have a great influence on crack behaviors and strength. Zhang et al. [12] 
theoretically studied the propagation mechanism of an open crack and a closed flaw; they also revealed mechanical characteristics of a closed flaw under in-plane biaxial compression. The above researches about closed flaws can provide some helpful insights for further study of infilled flaws. However, the materials on both sides of the closed flaw surface are often the same, while the materials on both sides of the infilled flaw surface are different; the interaction between grouting materials and rock materials was not considered in these researches about closed flaws.

To the authors' best knowledge, studies focused on mechanical property and crack propagation of samples with infilled flaws were limit. Le et al. [13] made a comparison of compressive strength, deformation behaviors, and crack propagation in samples containing single open and groutinfilled flaw; they found that grouting contributes to the improvement of the strength of the flawed samples and revealed that the reinforcement effect was affected by the flaw geometry. Miao et al. [14] performed uniaxial compressive tests on sandstone specimens containing a single open flaw, gypsum-infilled flaw, cement-infilled flaw, or resin-infilled flaw with different flaw inclination angles. The experimental results show that the existence of infilling materials suppressed the tensile stress and the type of infilling materials has an influence on the crack initiation stress. Moreover, samples with an open flaw have smaller crack initiation stress and larger crack inclination angle than samples with an infilled flaw. Zhao et al. [15] performed direct shear tests on rock-like samples with single clay infilled joint and found that the shear strength and crack behavior of rock-like samples with single clay infilled joint are affected by the joint roughness coefficient, the infill thickness to joint asperity amplitude ratio, the type of infill materials, and the applied normal stress. The above studies only consider the influence of a single infilled flaw in rock masses. The influence of multiple infilled flaws on the mechanical behavior of the rock mass is still poorly understood.

The main objective of this study is to analyze the mechanical behavior of grouted samples by observing microcrack development and to obtain the influence of flaw geometry and flaw spatial distribution on the mechanical behavior of rock masses with infilled flaws. The discrete element method (DEM) is widely used for simulating crack propagation in samples with single or multiple flaws [16-23]. In the discrete element model, the rock material is regarded as a heterogeneous body composed of cemented particles, in which the particles are deformable and the contact between particles may break. Therefore, cracks can be produced by the bond rupture between particles of the model, which is expected to be more realistic for representing crack behaviors and failure of rock samples.

\section{Methodology}

In this research, a two-dimensional particle flow code $\left(\mathrm{PFC}^{2 \mathrm{D}}\right)$ was selected for simulating uniaxial compression tests. A PFC ${ }^{2 \mathrm{D}}$ model represents modeling material and grouting material through rigid discs bonded at the contact points. Potyondy and Cundall [24] introduced a samplegenesis procedure, which is used to produce a rectangular specimen with a height of $100 \mathrm{~mm}$ and a width of $50 \mathrm{~mm}$ in this research. Two types of specimens were considered in this study: (1) samples with two parallel open flaws; (2) samples with two parallel infilled flaws. In these two types of specimens, the thickness of the flaw is set to $1 \mathrm{~mm}$, the flaw length $2 a$ is set to $10 \mathrm{~mm}$, the bridge length $2 b$ is set to $10 \mathrm{~mm}$, the inclination angle of flaws $\alpha$ varies between $0^{\circ}$ and $90^{\circ}$ in intervals of $15^{\circ}$, and the bridge inclination angle $\beta$ varies between $60^{\circ}$ and $120^{\circ}$ in intervals of $30^{\circ}$ (Figure 1 ).

Lee and Jeon [25] show that the parallel-bond model can be more realistic for producing rock modeling; therefore, the parallel-bond model was used to produce the rock model in this research. Delete the particles within the range of open flaws to obtain a model with open flaws (Figure 1(a)). When preparing the numerical model with infilled flaws, the simulation of the interface between grouting material and rock material is a difficult point. Zhao and Zhou [26] used $\mathrm{PFC}^{2 \mathrm{D}}$ to study failure patterns of rock specimens with grout-infilled fissures; the parallel-bond model was used for simulation of the interface between grouting material and rock material. When the parallel-bond model was used for simulation, particles whose centers lie on the opposite sides of the interface rotated along the tangent line of the contact point of these two balls, which lead to irrational phenomenon such as preliminary dilation (Figure 2(a)). Therefore, it is unsuitable to select the parallel-bond model to model the interface between the rock material and the grouting material. To solve this problem, the smooth joint model was proposed for simulation of the interface between grouting material and rock material. By using the smooth joint model, the particles on the opposite sides of the interface of modeling material and grouting material can cross each other by sliding along the interface (Figure 2(b)). In this research, when producing a numerical model with infilled flaws, the parallel-bond model was selected to produce modeling rock material and grouting material and the smooth joint model was used to model the interface between grouting material and rock material (Figure 1(b)).

Calibration tests were conducted to obtain microparameters of modeling material and grouting material. A thorough description of calibration tests was found in Potyondy and Cundall [24], so details about the calibration test are not repeated in this research. The microparameters values selected for the parallel-bond model of the modeling material and grouting material are listed in Table 1, respectively. The results of calibration tests demonstrate that the microparameters are able to reproduce the macroproperties of rock material and grouting material, respectively (Table 2).

In the study of Zhao and Zhou [26], the parameters of the interface between grouting material and rock material were the average value of rock material and grouting material. In fact, this method of determining parameters is unreasonable. Calibration tests should be performed to obtain the parameters of the interface. In this research, the smooth joint model for simulating the interface is activated with five parameters: friction coefficient, tensile strength, 


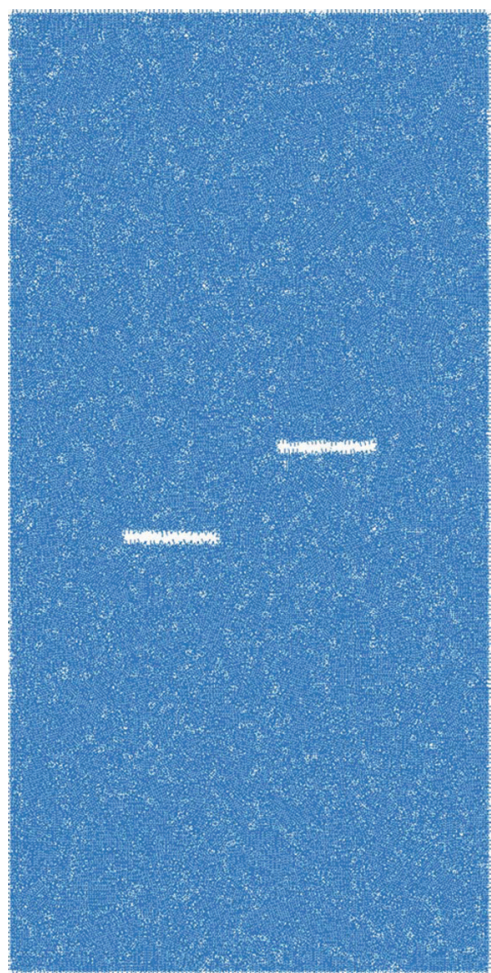

(a)

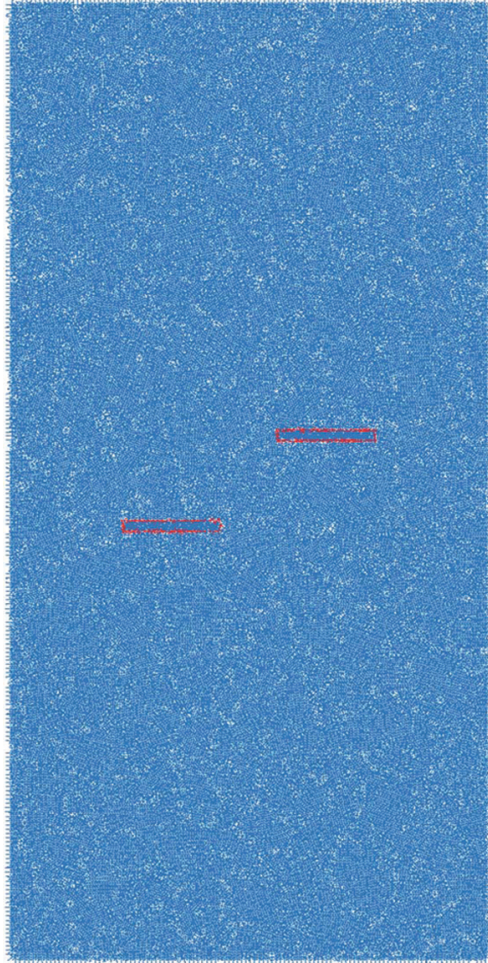

(b)

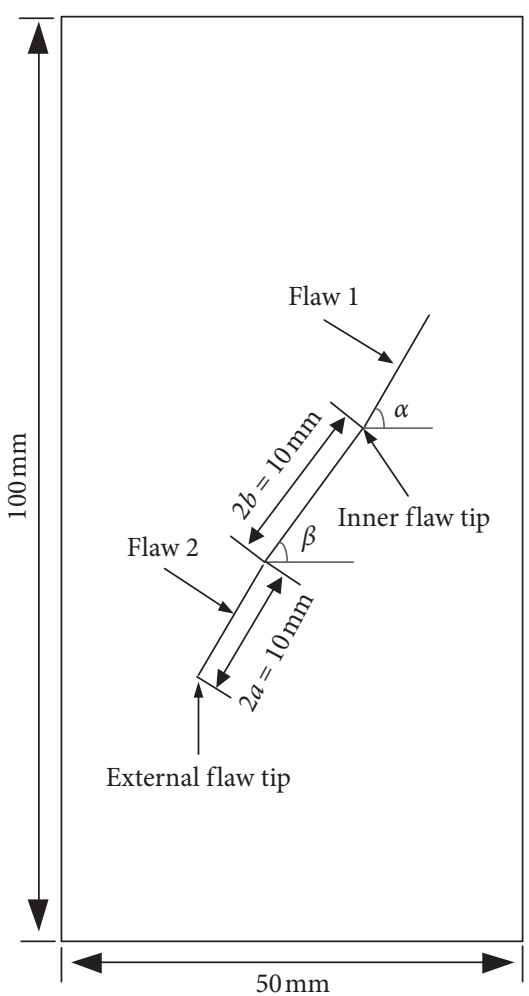

(c)

FIGURE 1: Numerical models used for producing samples with open flaws or infilled flaws (blue line represents parallel-bond contact and the red line represents smooth joint contact). (a) Open flaws. (b) Infilled flaws. (c) Flaw geometry.

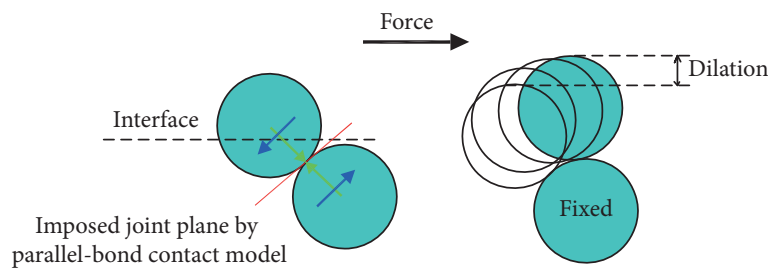

(a)

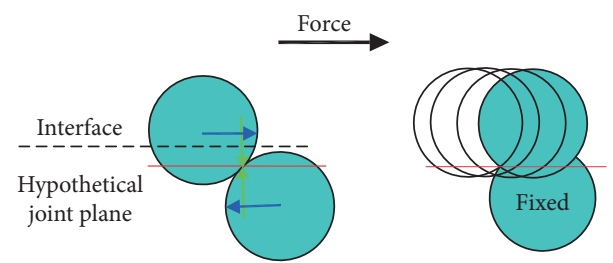

(b)

FIGURE 2: The movement direction of balls in (a) a parallel-bond contact model and (b) a smooth joint contact model (Mehranpour and Kulatilake [27]).

TABLE 1: Microparameters for simulating rock and grout.

\begin{tabular}{|c|c|c|c|c|c|}
\hline Ball & Rock & Grout & Parallel bond & Rock & Grout \\
\hline Rmin & 0.2 & 0.1 & Modulus (GPa) & 10 & 2 \\
\hline $\mathrm{Rmax} / \mathrm{Rmin}$ & 1.25 & 1.25 & Ratio of normal to shear stiffness & 1.5 & 1.3 \\
\hline Density & 2700 & 2500 & Normal strength $(\mathrm{MPa})$ & 13 & 5 \\
\hline Contact modulus (GPa) & 10 & 2 & Shear strength $(\mathrm{MPa})$ & 13 & 5 \\
\hline Ratio of normal to shear stiffness & 1.5 & 1 & Radius multiplier & 1.0 & 1.0 \\
\hline Contact friction coefficient & 0.5 & 0.5 & & & \\
\hline
\end{tabular}

TABLE 2: Material properties of real and numerical samples.

\begin{tabular}{lcccc}
\hline \multirow{2}{*}{ Mechanical parameters } & Rock & \multicolumn{2}{c}{ Grout } \\
& Laboratory test & Numerical test & Laboratory test & Numerical test \\
\hline Uniaxial compressive strength $(\mathrm{MPa})$ & 39.2 & 38.8 & 13.4 & 13.5 \\
Elastic modulus $(\mathrm{GPa})$ & 21.2 & 24.2 & 4.7 & 5.0 \\
Poisson's ratio & 0.18 & 0.18 & 0.16 & 0.15 \\
\hline
\end{tabular}


cohesion, normal stiffness, and shear stiffness. Calibration tests were conducted to obtain these parameters, and Figure 3 shows the numerical shear model for calibration tests. The numerical shear model consists of two blocks. The height and width of the block are $25 \mathrm{~mm}$ and $50 \mathrm{~mm}$, respectively. The parallel-bond contact model was selected for these two blocks and the smooth joint model was selected for the interface between these two blocks. Different microparameters of the smooth joint contact model were specified, and the direct shear test was conducted on the $\mathrm{PFC}^{2 \mathrm{D}}$ model. If the cohesive force and friction angle obtained by the numerical test were basically consistent with friction angle and the cohesive force of the interface obtained by the laboratory test, then the microparameters of microparameters for a smooth joint contact model were considered to be suitable. The specified values of the smooth joint contact model are given in Table 3.

The numerical specimens with two parallel open flaws or grouting-infilled flaws were subjected to uniaxial compressive stress. The loading rate of the upper and lower walls is $0.01 \mathrm{~m} / \mathrm{s}$, and it is low enough to ensure the quasistatic equilibrium state of specimens under uniaxial compressive stress.

\section{Results and Discussion}

3.1. Open Flaw Case. Figure 4 shows the crack development process of samples containing unfilled flaws having different flaw inclination angles of $0^{\circ}, 45^{\circ}$, and $90^{\circ}$ and the same bridge inclination angle of $120^{\circ}$ under uniaxial compressive stress. It can be seen that when $\alpha=0^{\circ}$, tensile cracks initiate from the middle part and tips of open flaws and finally form a closed ring. Cracks initiated when the stress reaches 0.55 times the peak stress. When $\alpha=45^{\circ}$, tensile cracks emanate from the tips of open flaws and develop along the loading direction. In the postpeak stage, the rock bridge was penetrated by tensile cracks. Cracks were observed when the stress reaches 0.65 times the peak stress. For the samples with $\alpha=90^{\circ}$, the tensile crack was not observed at the tips of open flaws when the loading stress reached the peak stress. In the postpeak stage, the rock bridge was not cut through. Cracks initiate when the stress reaches 0.8 times the peak stress, which means that the crack initiation stress is close to the peak stress. Comparing the crack development process of samples with different flaw inclination angles, it was found that the initiation position of the tensile crack was shifted from the middle part of open flaws to the tips of open flaws as $\alpha$ increases from $0^{\circ}$ to $45^{\circ}$. In addition, tensile cracks were hardly to initiate from the tip of open flaws with a relatively large flaw inclination angle. Figure 4 shows that the ratio of crack initiation stress to peak stress increases as the increases of flaw inclination angle, which indicates that it is more difficult for cracks to initiate as the flaw inclination angle increases.

Figure 5 shows the contact force chain of samples containing unfilled flaws having different flaw inclination angles of $0^{\circ}, 45^{\circ}$, and $90^{\circ}$ and the same bridge inclination angle of $120^{\circ}$ under uniaxial compressive stress. It shows that when $\alpha=0^{\circ}$, the tension was concentrated in the middle area

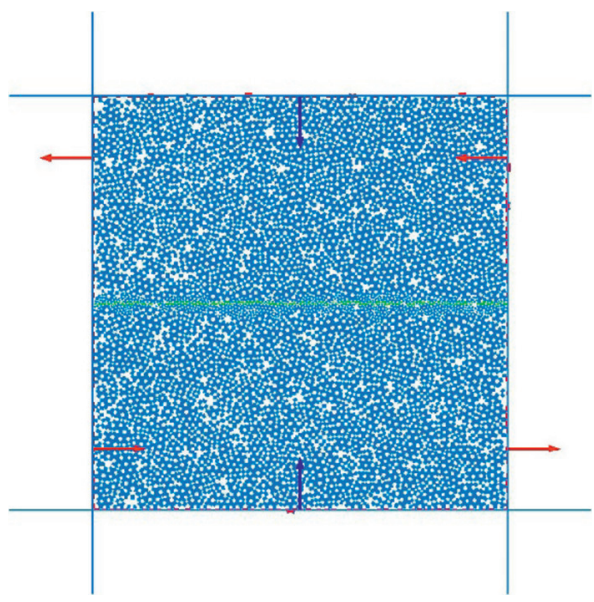

FIgURE 3: The numerical shear model for calibration tests (blue line represents parallel-bond contact and the green line represents smooth joint contact).

TABLe 3: Mechanical parameters selected for the smooth joint contact model.

\begin{tabular}{lc}
\hline Mechanical parameters & Assigned smooth joint value \\
\hline Normal stiffness $\left(\mathrm{N} / \mathrm{m}^{3}\right)$ & $1 \times 10^{10}$ \\
Shear stiffness $\left(\mathrm{N} / \mathrm{m}^{3}\right)$ & $1 \times 10^{9}$ \\
Friction coefficient & 0.2 \\
Cohesion $(\mathrm{MPa})$ & 0.1 \\
Tensile strength $(\mathrm{MPa})$ & 0.1 \\
\hline
\end{tabular}

of the open flaw, and the compression was concentrated in the tips of the open flaw at the initial stage of loading. Therefore, the tensile crack was first emanated in the middle area of the open flaw. After the tensile crack occurred, the tension concentration in the middle area of the open flaw was reduced. When $\alpha=45^{\circ}$, the tension was concentrated in the tips of the open flaw at the initial stage of loading, which leads to the occurrence of tensile cracks. When $\alpha=90^{\circ}$, there was no tension concentration as the loading stress increases to peak strength, so no obvious tensile cracks were produced. The inclination angle of open flaws has an influence on the distribution of the tension concentration area. Tensile crack was firstly generated at the tension concentration area and led to the release of energy. Moreover, the tension concentration in this area was reduced after the occurrence of tensile cracks.

Figure 6 shows the crack development process of samples containing unfilled flaws with different bridge inclination angles of $60^{\circ}, 90^{\circ}$, and $120^{\circ}$ and the same flaw inclination angle of $75^{\circ}$ under uniaxial compressive stress. When $\beta=60^{\circ}$ and $90^{\circ}$, tensile crack initiated from the tips of open flaws had a really limited extension distance until the loading stress reached the peak stress. In the postpeak stage, the rock bridge was penetrated by tensile cracks. When $\beta=120^{\circ}$, the rock bridge was not penetrated, and the final failure surface of the sample did not pass through the rock bridge. This shows that when the inclination angle of the rock bridge is $120^{\circ}$, the upper fissure has a shielding effect on the lower fissure, and the rock bridge is not easy to be 

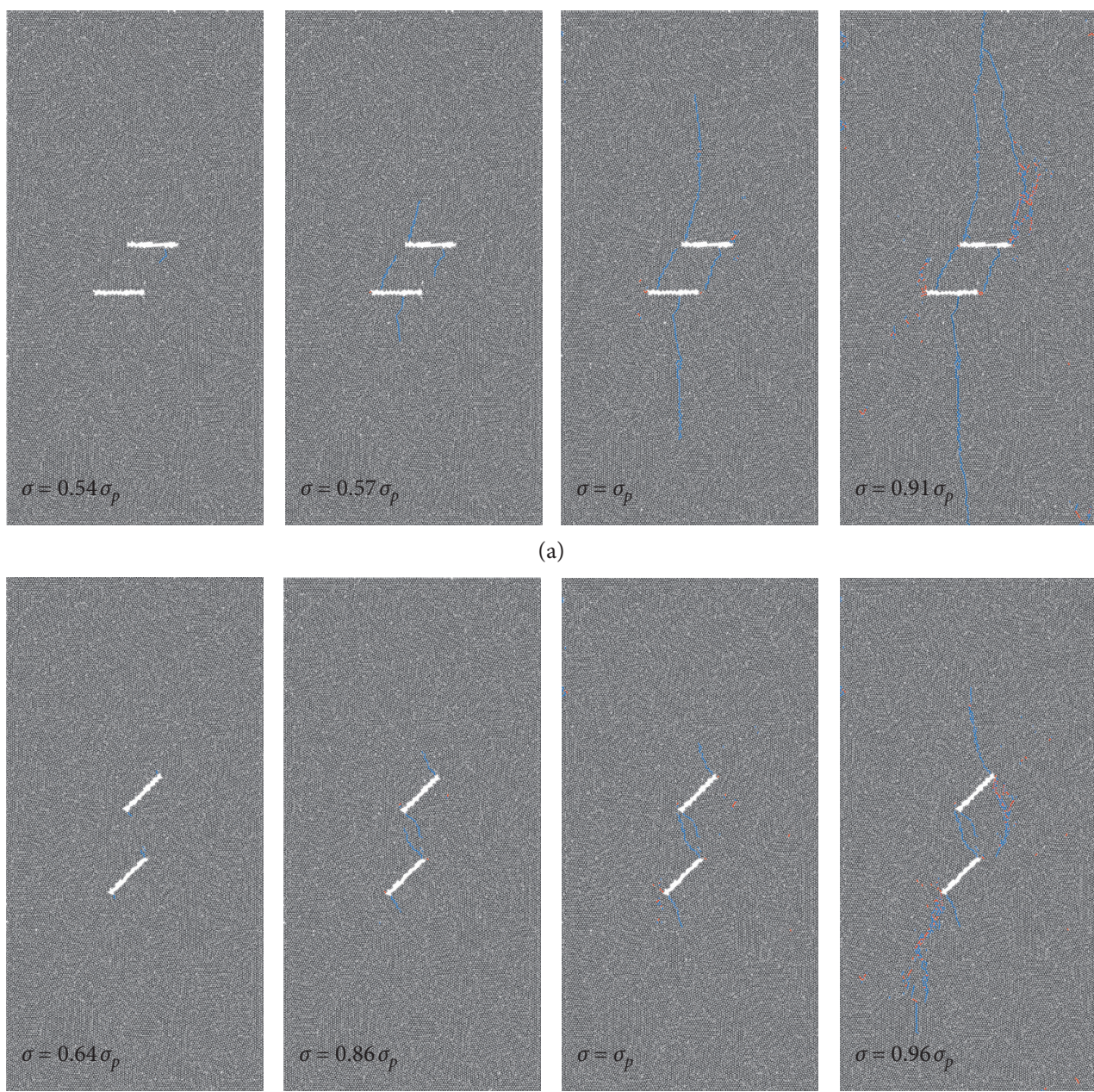

(a)
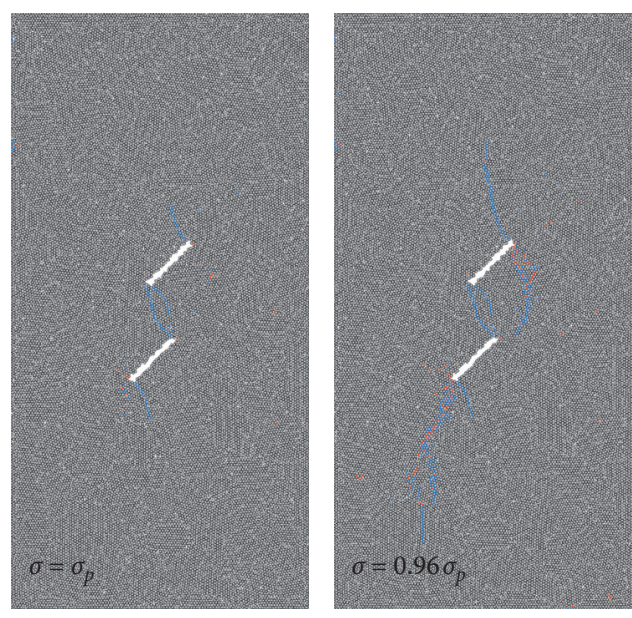

(b)
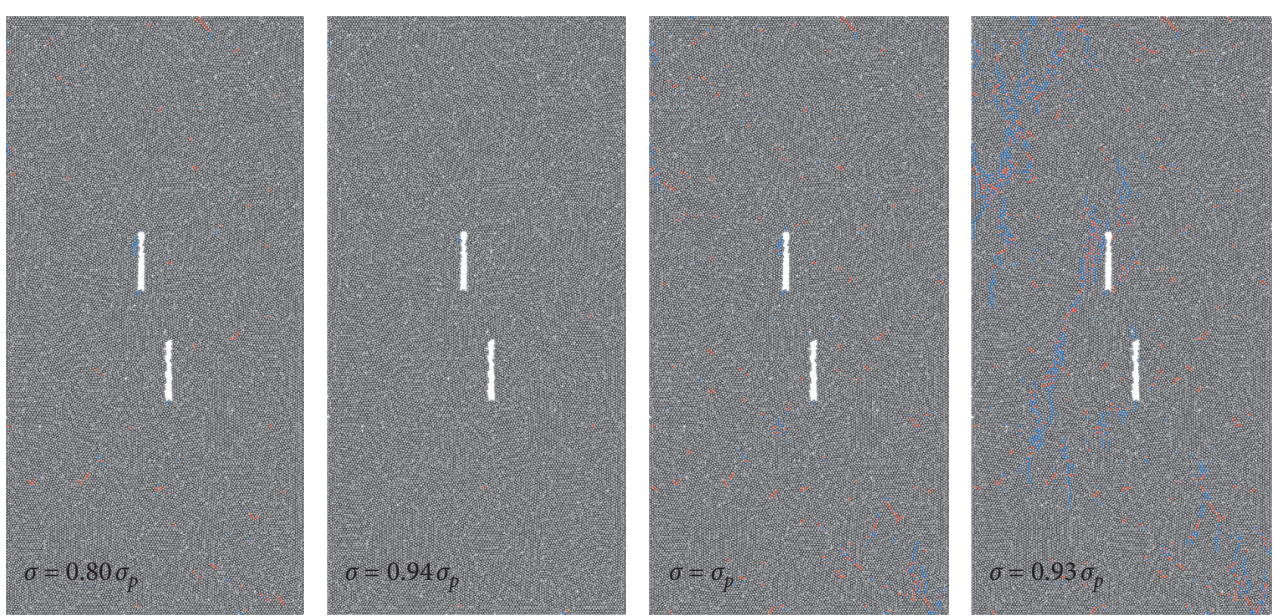

(c)

Figure 4: Crack development process of samples containing unfilled flaws with the same $\beta$ of $120^{\circ}$ and different $\alpha$ of $0^{\circ}, 45^{\circ}$, and $90^{\circ}$ (blue cracks represent tensile cracks and red cracks represent shear cracks). (a) $\alpha=0^{\circ}$ and $\beta=120^{\circ}$; (b) $\alpha=45^{\circ}$ and $\beta=120^{\circ}$; (c) $\alpha=90^{\circ}$ and $\beta=120^{\circ}$.

damaged. From Figure 6, it can be seen that, for the samples with varying bridge inclination angles, the ratio of the crack initiation stress to the peak stress of the samples is very close.

Contact force chain of samples containing unfilled flaws with different bridge inclination angles of $60^{\circ}, 90^{\circ}$, and $120^{\circ}$ and the same flaw inclination angle of $75^{\circ}$ is given by Figure 7 . It is found that, at the initial stage of loading, there was no tension concentration at the tip of open flaws, so no obvious tensile cracks were produced. Before reaching the peak strength, the rock bridge area was dominated by 

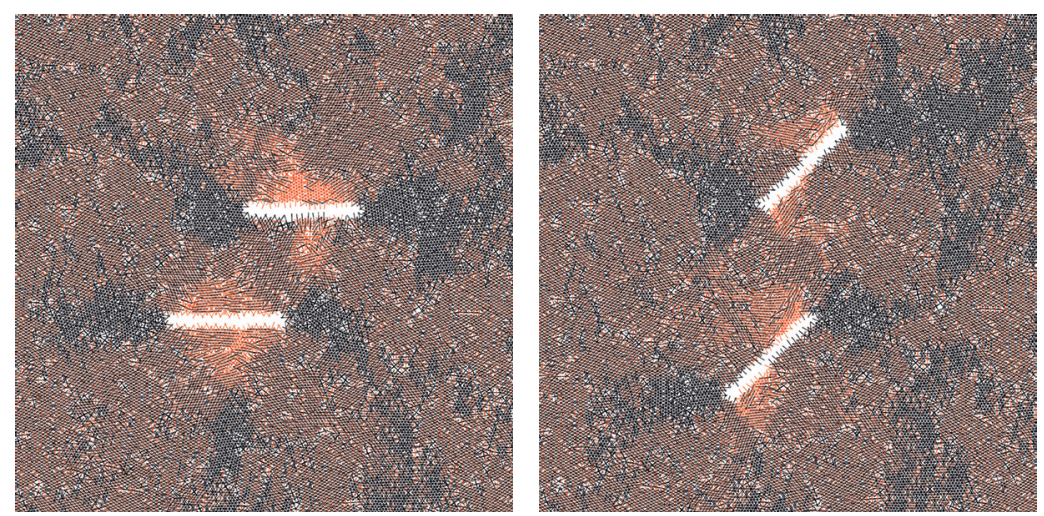

(a)
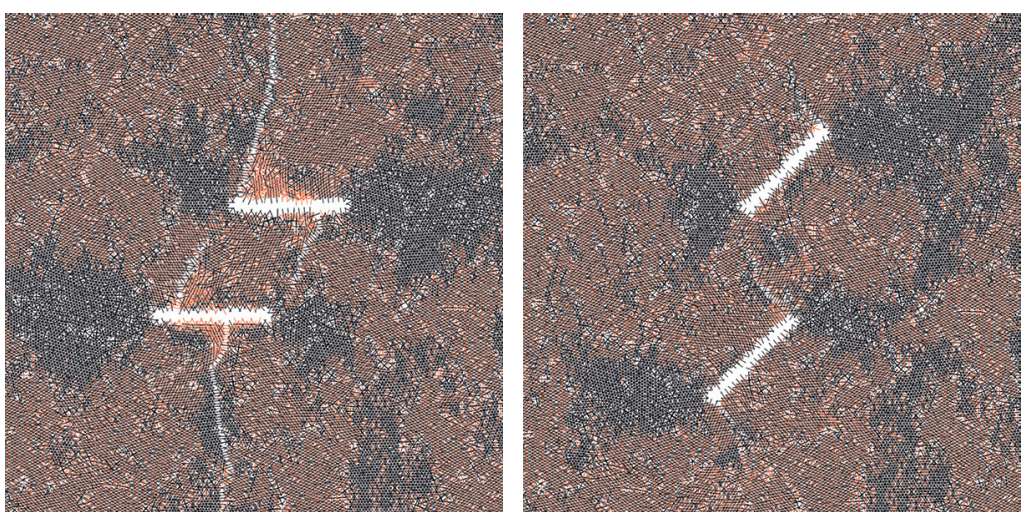

(b)
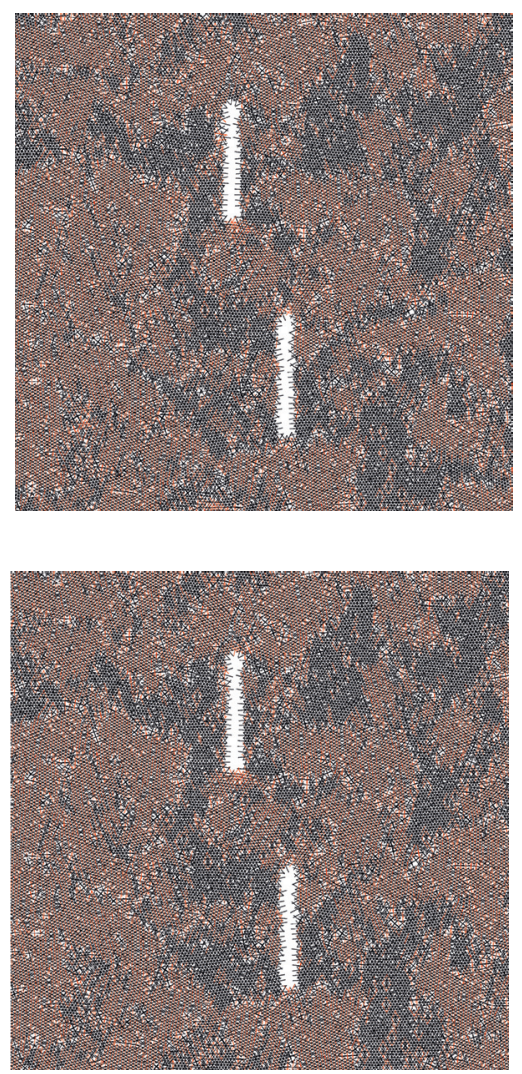

Figure 5: Contact force chain of samples containing unfilled flaws with the same $\beta$ of $120^{\circ}$ and different $\alpha$ of $0^{\circ}, 45^{\circ}$, and $90^{\circ}$ at the (a) crack initiation moment and (b) peak stress moment (red contact force chain represents tension and black contact force chain represents compression).

compressive stress, so no tensile cracks occurred in the rock bridge area. In the postpeak stage, when $\beta=90^{\circ}$ and $60^{\circ}$, the rock bridge area was mainly subjected to tensile stress, which leads to the occurrence of tensile cracks. When $\beta=120^{\circ}$, the rock bridge area was mainly subjected to compressive stress and no tensile cracks emanated in the rock bridge area, which means that the rock bridge was not damaged by tensile cracks.

3.2. Infilled Flaw Case. Figure 8 shows the crack development process of samples containing infilled flaws with different flaw inclination angles of $0^{\circ}, 45^{\circ}$, and $90^{\circ}$ and the same bridge inclination angle of $90^{\circ}$ under uniaxial compressive stress. It can be seen that when $\alpha=0^{\circ}$, tensile crack emanated from the middle part and tips of infilled flaws at the initial stage of loading. The rock bridge was penetrated by tensile cracks when the loading stress reached the peak strength. The grouting material was cut by tensile cracks in the postpeak stage. When $\alpha=45^{\circ}$, tensile crack emanated from the inner and external tips of infilled flaws at the initial stage of loading and the shear crack occurred at the interface between the model material and grouting material in the postpeak stage. The rock bridge was penetrated by tensile cracks. When $\alpha=90^{\circ}$, no tensile cracks occurred at the rock bridge area, and the rock bridge was not penetrated during the compressive tests. Comparing the crack development process of samples containing two parallel infilled flaws with varying flaw inclination angles, it can be seen that the flaw inclination angle has a significant effect on the crack propagation process of grouting samples. Le et al. [13] conducted experimental tests on samples with grout-infilled flaws; they found that shear cracks occurred in the interface between grouting material and rock material, and tensile crack occurred in the grouting material. The phenomena showed by Le et al. [13] cannot be simulated by the parallelbond contact model (Zhao and Zhou [26]). In this research, by using the smooth joint model, the occurrence of shear cracks at the interface and tensile cracks in the grouting material has been successfully simulated. It indicates that it is appropriate to simulate the interface with the smooth joint model, which may provide some help for the following researchers to simulate the interface of grouting materials.

The contact force of samples containing infilled flaws with the same bridge inclination angle of $90^{\circ}$ and different flaw inclination angles of $0^{\circ}, 45^{\circ}$, and $90^{\circ}$ was shown in Figure 9. The large values stand for compressive forces and the small ones represent tensile forces. Compression does not cause the break of contact, but tension can cause the break of contact, so the distribution of tension is the most concerned focus in this research. It can be seen from Figure 9 that, in the case of $\alpha=0^{\circ}$, at the initial stage of loading, 

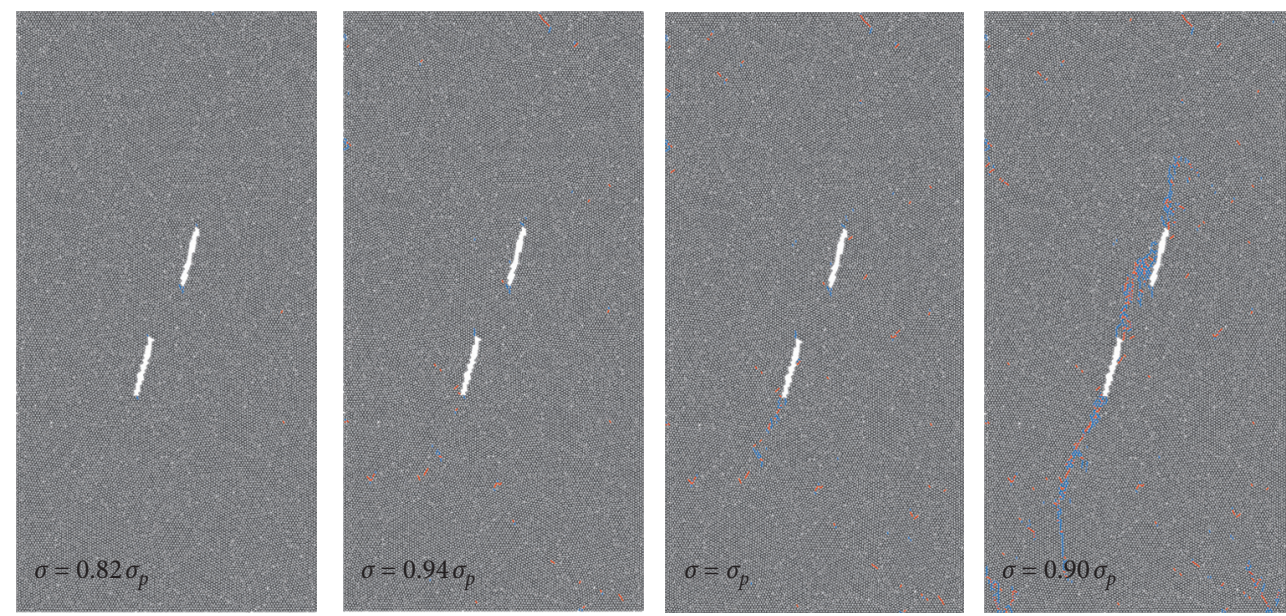

(a)
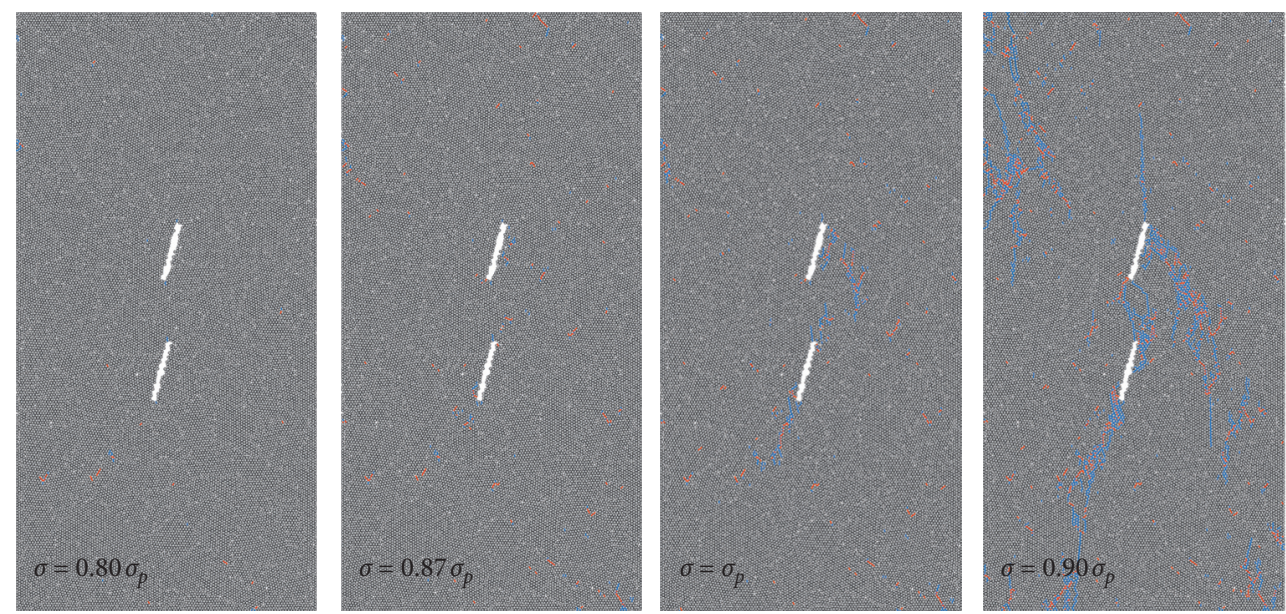

(b)
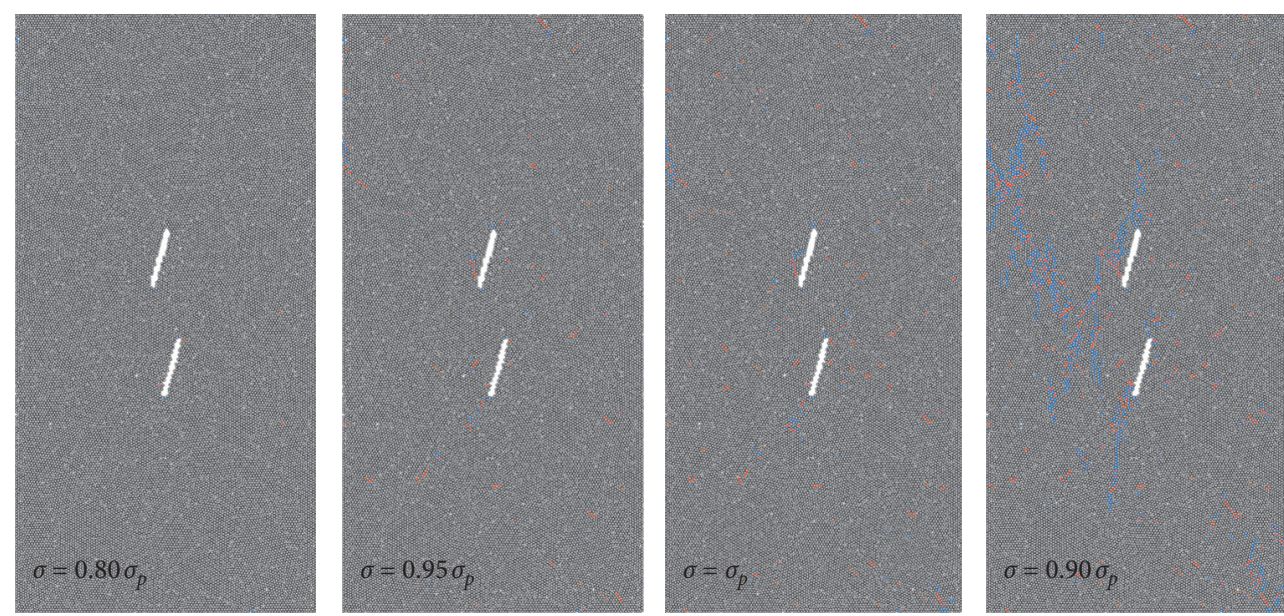

(c)

FiguRE 6: Crack development process of samples containing unfilled flaws with the same $\alpha$ of $75^{\circ}$ and different $\beta$ of $60^{\circ}$, 90 $0^{\circ}$, and $120^{\circ}$ (blue cracks represent tensile cracks and red cracks represent shear cracks) (a) $\alpha=75^{\circ}$ and $\beta=60^{\circ}$. (b) $\alpha=75^{\circ}$ and $\beta=90^{\circ}$. (c) $\alpha=75^{\circ}$ and $\beta=120^{\circ}$.

particles in the middle area of infilled flaws were subjected to a tensile force of $0.141 \mathrm{~N}$, which leads to the occurrence of tensile cracks in the middle area of infilled flaws. When the loading stress reached the peak stress, the grouting material was still subjected to a certain tensile stress of $0.168 \mathrm{~N}$, which causes the generation of tensile cracks. When $\alpha=45^{\circ}$, the tensile force was concentrated in the tips of infilled flaws at the initial stage of loading, which leads to the occurrence of tensile cracks in the tips of infilled flaws. At the initial stage of loading, the tensile force of particles in the tips of infilled 

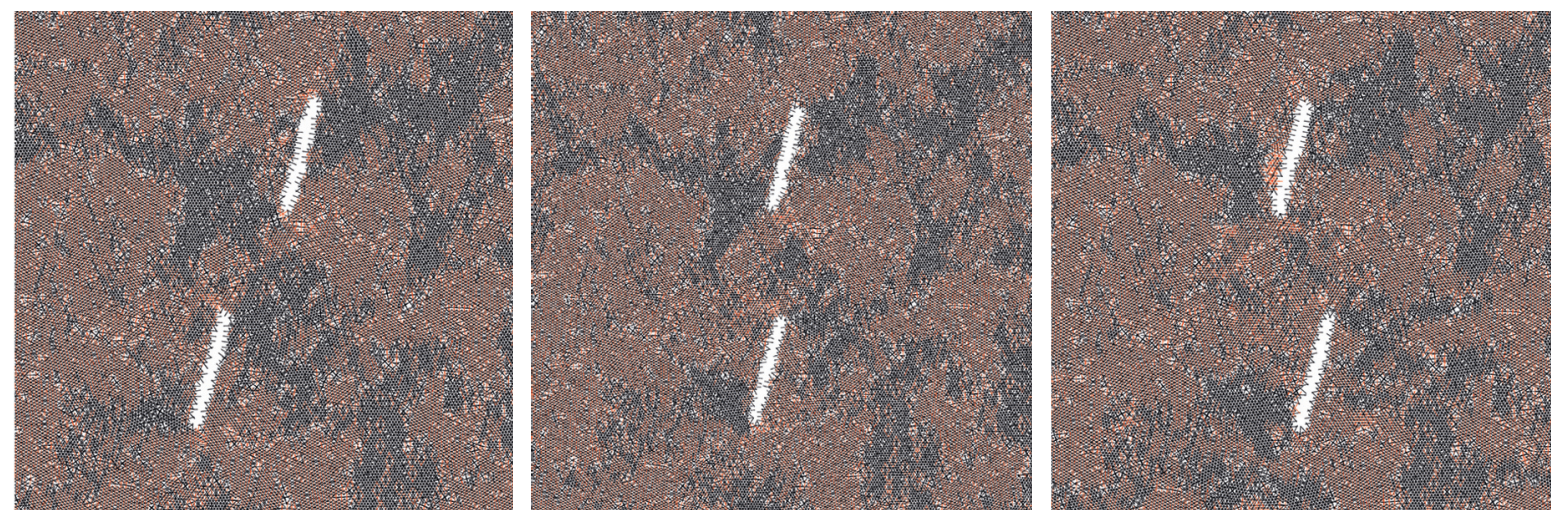

(a)
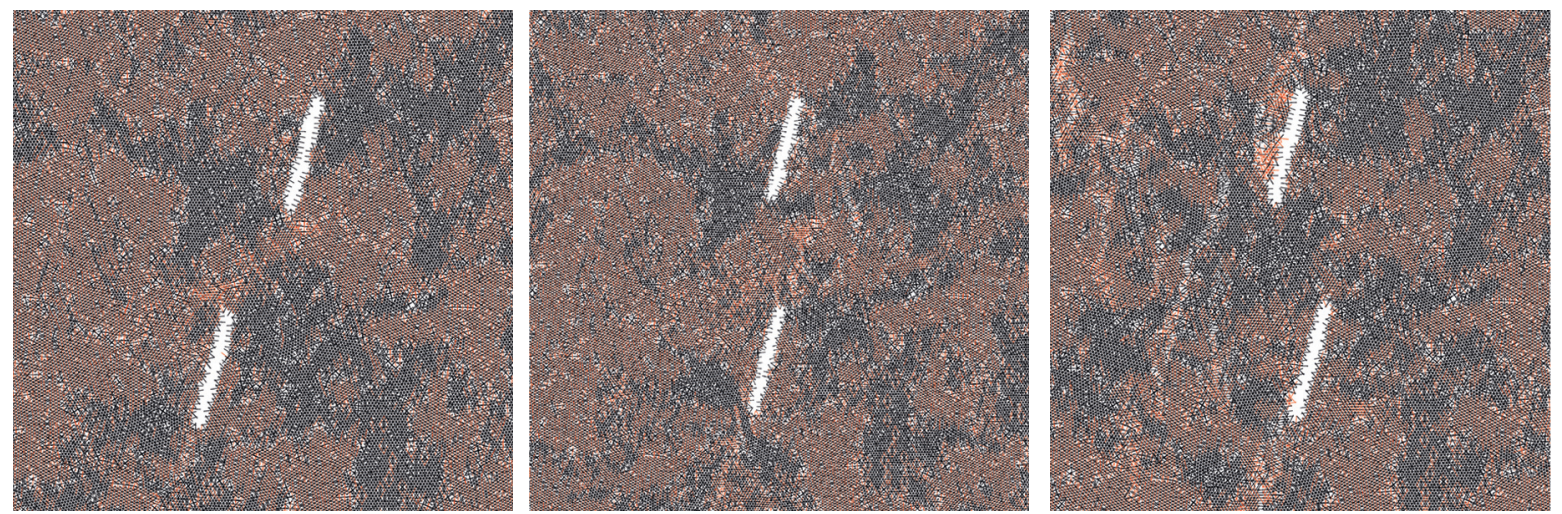

(b)

Figure 7: Contact force chain of samples containing unfilled flaws with the same $\alpha$ of $75^{\circ}$ and different $\beta$ of $60^{\circ}, 90^{\circ}$, and $120^{\circ}$ at the (a) crack initiation moment and (b) peak stress moment (red contact force chain represents tension and black contact force chain represents compression).
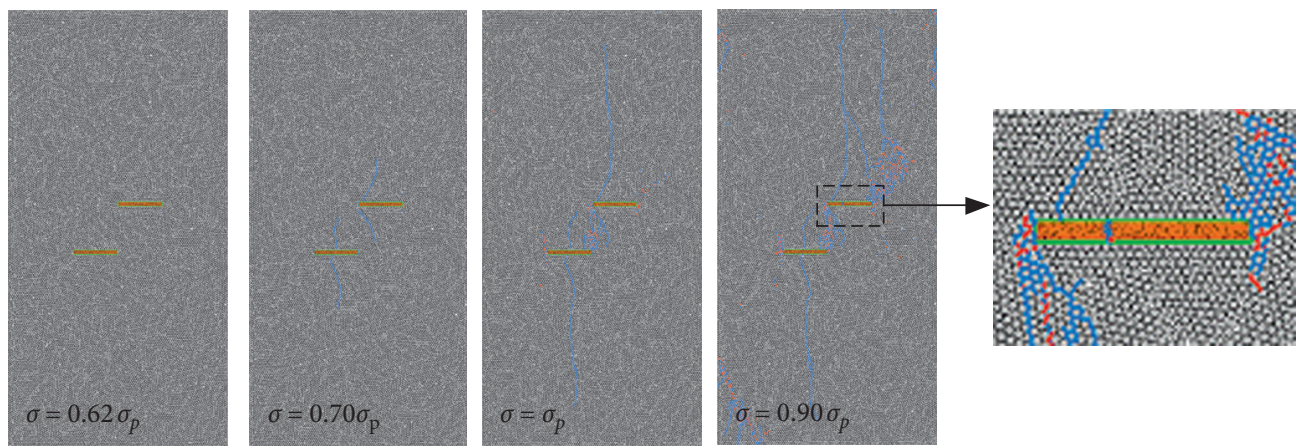

(a)
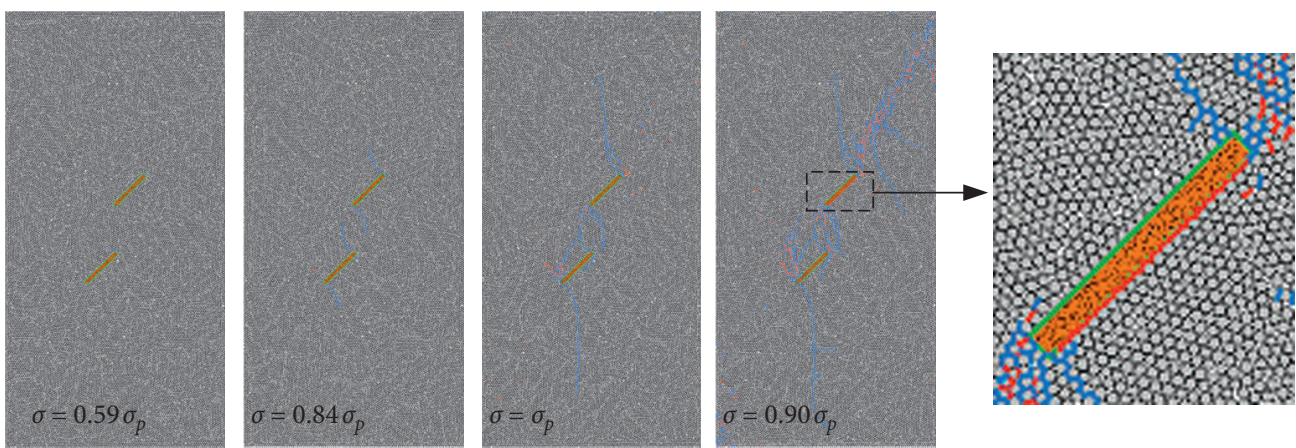

(b)

FIGURE 8: Continued. 

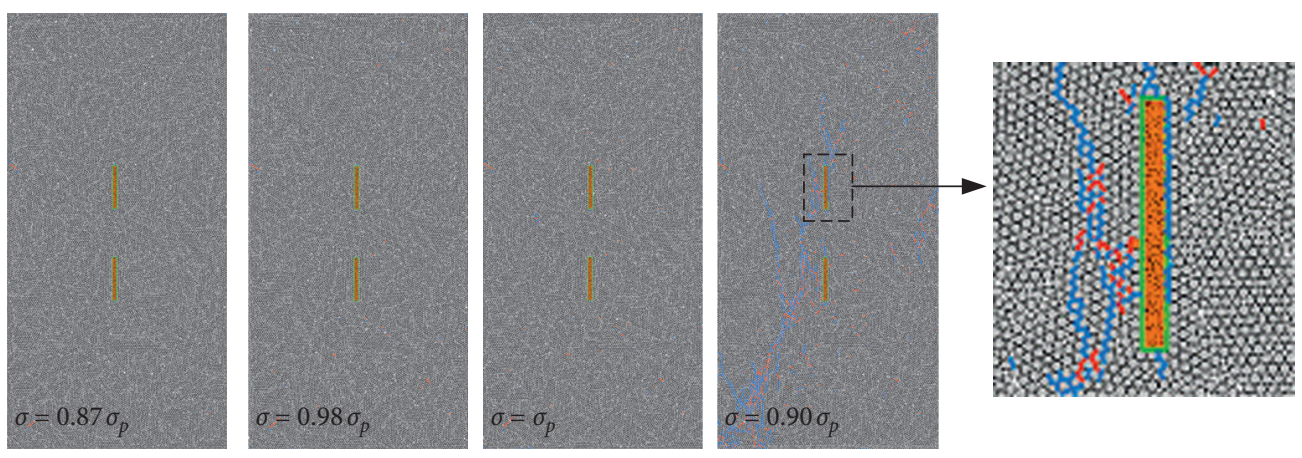

(c)

Figure 8: Crack development process of samples containing infilled flaws with the same $\beta$ of $90^{\circ}$ and different $\alpha$ of $0^{\circ}, 45^{\circ}$, and $90^{\circ}$ (blue lines represent tensile cracks and red lines represent shear cracks). (a) $\alpha=0^{\circ}$ and $\beta=90^{\circ}$, (b) $\alpha=45^{\circ}$ and $\beta=90^{\circ}$, (c) $\alpha=90^{\circ}$ and $\beta=90^{\circ}$.

flaws with $\alpha=45^{\circ}$ was $0.078 \mathrm{~N}$, which was smaller than the tensile force of particles in the tips of the infilled flaws with $\alpha=0^{\circ}$. It indicates that as the flaw inclination angle increases, the tensile force near the infilled flaws reduces. When $\alpha=90^{\circ}$, there was no stress concentration near the crack during the loading process and no obvious tensile cracks were produced in the tips of infilled flaws. It is found that the internal stress distribution of the modeling material and the grouting material was affected by the flaw inclination angle.

Figure 10 shows the crack development process of samples containing infilled flaws with different bridge inclination angles of $60^{\circ}, 90^{\circ}$, and $120^{\circ}$ and the same flaw inclination angle of $75^{\circ}$. When the loading stress reached the peak stress, tensile cracks were not observed at the rock bridge area of samples with $\beta=90^{\circ}$ and $120^{\circ}$ but observed at the rock bridge area of samples with $\beta=60^{\circ}$. In the postpeak stage of loading, the rock bridge of samples with $\beta=60^{\circ}$ and $90^{\circ}$ was penetrated by tensile cracks, and the final failure path of the sample passed through the rock bridge, but the rock bridge of samples with $\beta=120^{\circ}$ was not penetrated by tensile cracks. It demonstrates that the bridge inclination angle has an obvious influence on the crack development process of samples containing infilled flaws.

The contact force of samples containing infilled flaws with the same flaw inclination angle of $75^{\circ}$ and different bridge inclination angles of $60^{\circ}, 90^{\circ}$, and $120^{\circ}$ is shown in Figure 11 . For the samples with bridge inclination angles of $60^{\circ}, 90^{\circ}$, and $120^{\circ}$, at the initial stage of loading, there is no obvious stress concentration at the tips of cement-infilled flaws, and the tensile force is very small; thus, no tensile crack was generated. It can be seen from Figure 11 that, at the postpeak stage of loading, particles in the samples with the bridge inclination angles of $60^{\circ}, 90^{\circ}$, and $120^{\circ}$ were subjected to the tensile force of $0.16 \mathrm{~N}, 0.14 \mathrm{~N}$, and $0.024 \mathrm{~N}$, respectively. It demonstrates that as the bridge inclination angle increases, the tensile force decreases, so the contact is not easy to break and the sample is not easy to be damaged. It demonstrates that the bridge inclination angle has a certain influence on the strength of samples containing infilled flaws.

Mechanical properties of the specimens with infilled flaws having different $\alpha$ and $\beta$ are shown in Table 4 . In the case of the same bridge inclination angle, the compressive strength, elastic modulus, and the crack initiation stress increase as the flaw inclination angle increases, while Poisson's ratio changes very little, which is consistent with the results obtained by Zhang and Wong [18]. Moreover, in the case of the same flaw inclination angle, as bridge inclination angle increases from $60^{\circ}$ to $90^{\circ}$, the compressive strength increases, the crack initiation stress decreases, and Poisson's ratio and the elastic modulus change very little.

\subsection{Comparison between Open Flaws or Infilled Flaws.} Taking the specimens containing open flaws and infilled flaws with a bridge inclination angle of $120^{\circ}$ and flaw inclination angles of $0^{\circ}, 45^{\circ}$, and $90^{\circ}$ as examples, the effects of grouting on the failure process and force of the specimen are analyzed. Figure 12 shows the crack development process of samples containing infilled flaws with the same bridge inclination angle of $120^{\circ}$ and different flaw inclination angles of $0^{\circ}, 45^{\circ}$, and $90^{\circ}$. By comparing Figures 4 and 12, it can be seen that the crack development process of the specimens containing open flaws and infilled flaws with the same flaw geometry is similar, which indicates that the impact of grouting on the crack development process is limited. In order to further understand the effect of grouting on the force of the specimen, the contact force of samples containing open and infilled flaws with the same flaw geometry when the loading stress reaches the crack initiation stress and peak strength (Figures 13 and 14) is analyzed. Figure 13 shows that when the loading stress reaches the crack initiation stress, the tensile force of particles of the grouting sample reduces, indicating that the grouting is beneficial to reduce the tensile force of the particles, which suppresses the generation of tensile cracks and improve the initiation stress of the sample. It can be seen from Figure 14 that when the loading stress reaches the peak stress, the tensile force of particles of samples containing infilled flaws is smaller than those containing open flaws, and it is hard to produce tensile cracks, which lead to the improvement of the peak strength of the sample. 


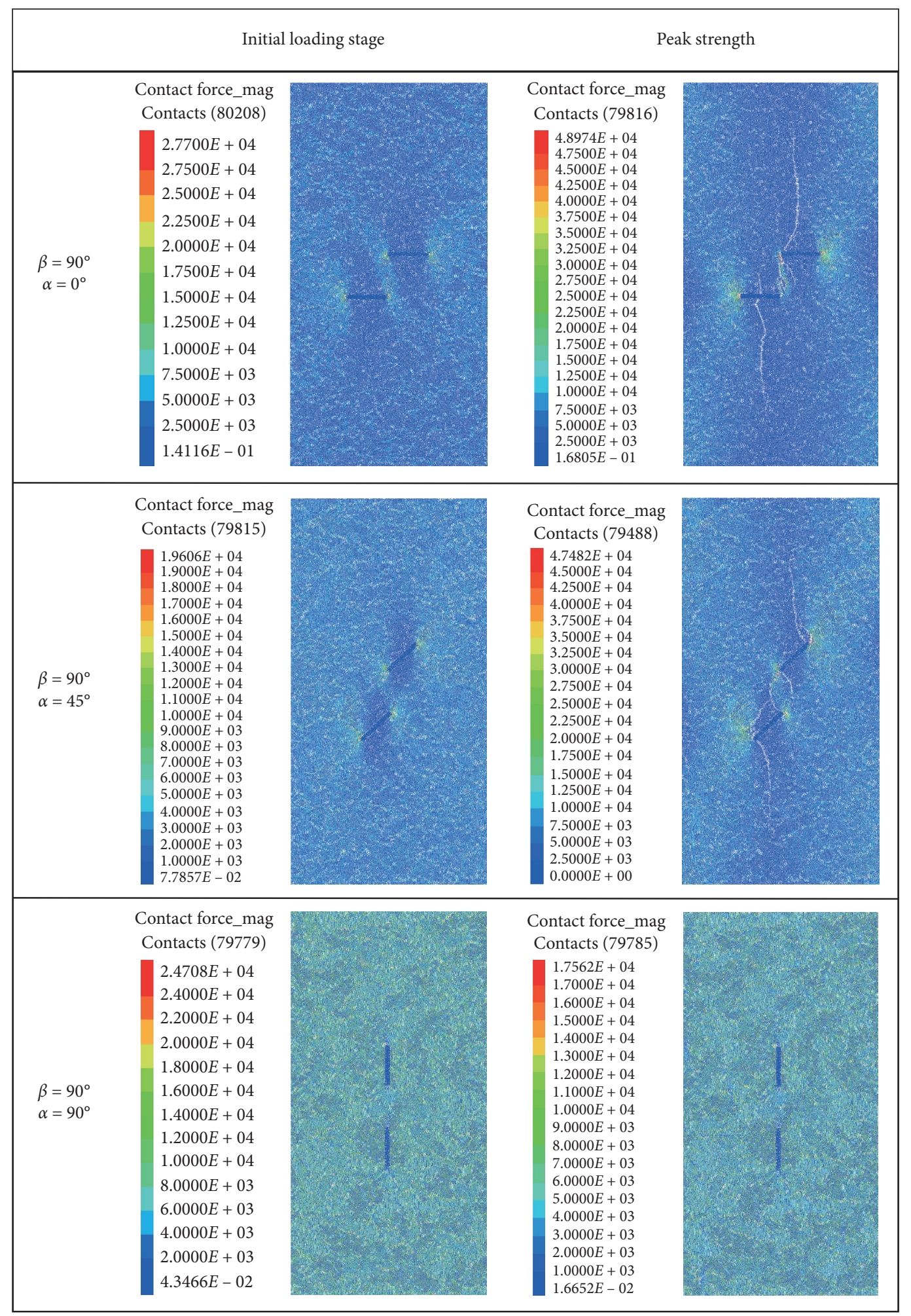

FIGURE 9: Contact force of samples containing infilled flaws with the same $\beta$ of $90^{\circ}$ and different $\alpha$ of $0^{\circ}, 45^{\circ}$, and $90^{\circ}$.

Table 5 shows mechanical properties of the samples with open flaws and infilled flaws having a bridge inclination angle of $120^{\circ}$ and flaw inclination angles of $0^{\circ}, 45^{\circ}$, and $90^{\circ}$ obtained from numerical tests. It can be seen that the compressive strength and crack initiation stress of the sample with infilled flaws are greater than the sample with open flaws, indicating that the grouting of cement can improve the initiation stress and strength of the sample. Poisson's ratio and elastic modulus of the samples with infilled flaws are close to the samples with open flaws, indicating that the influence of grouting of cement on Poisson's ratio and elastic modulus is limited. 

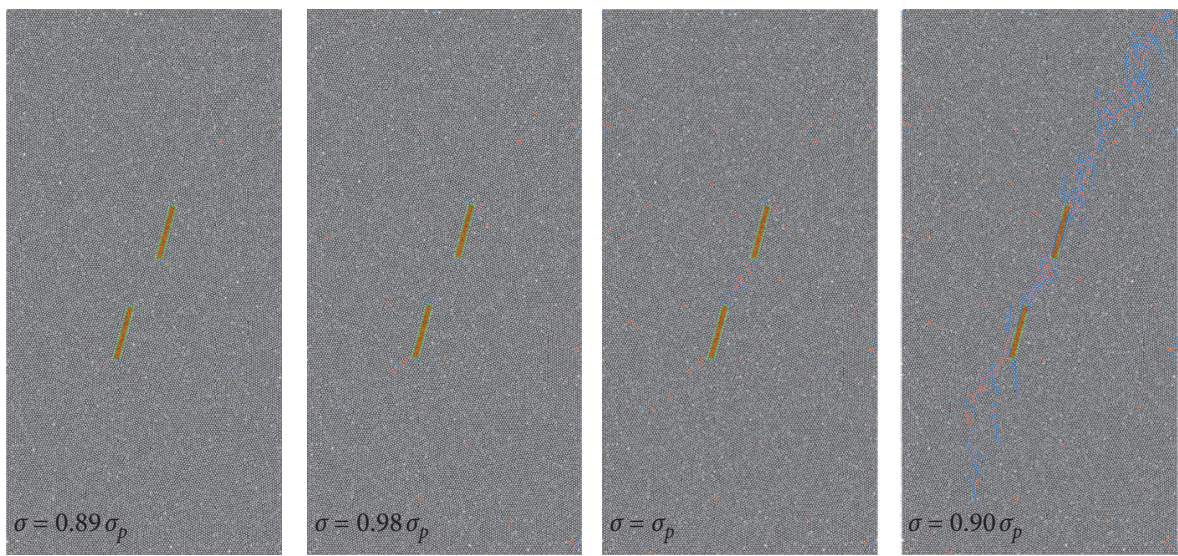

(a)
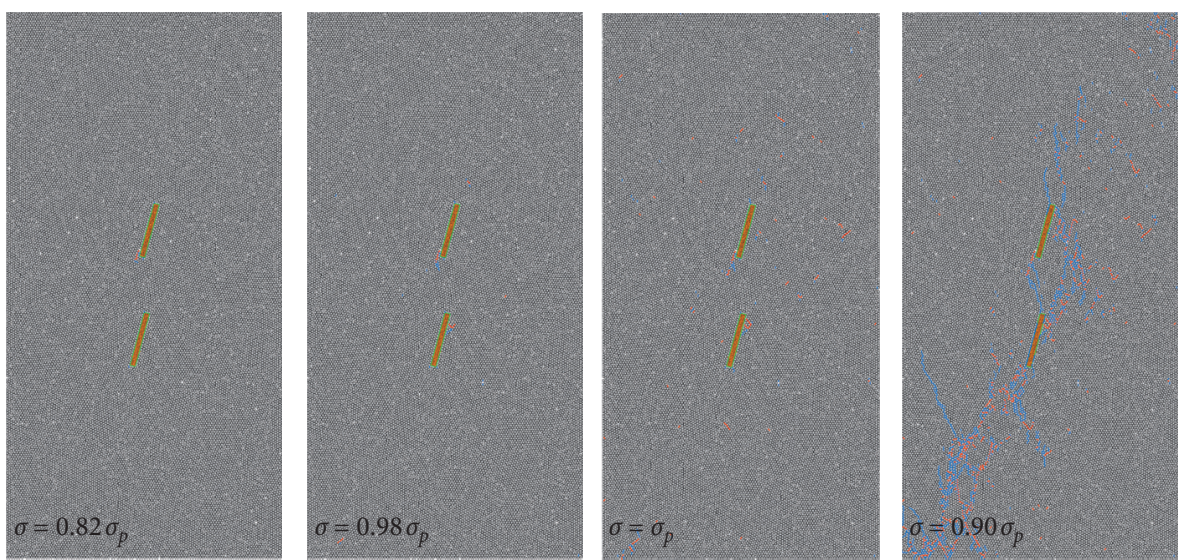

(b)
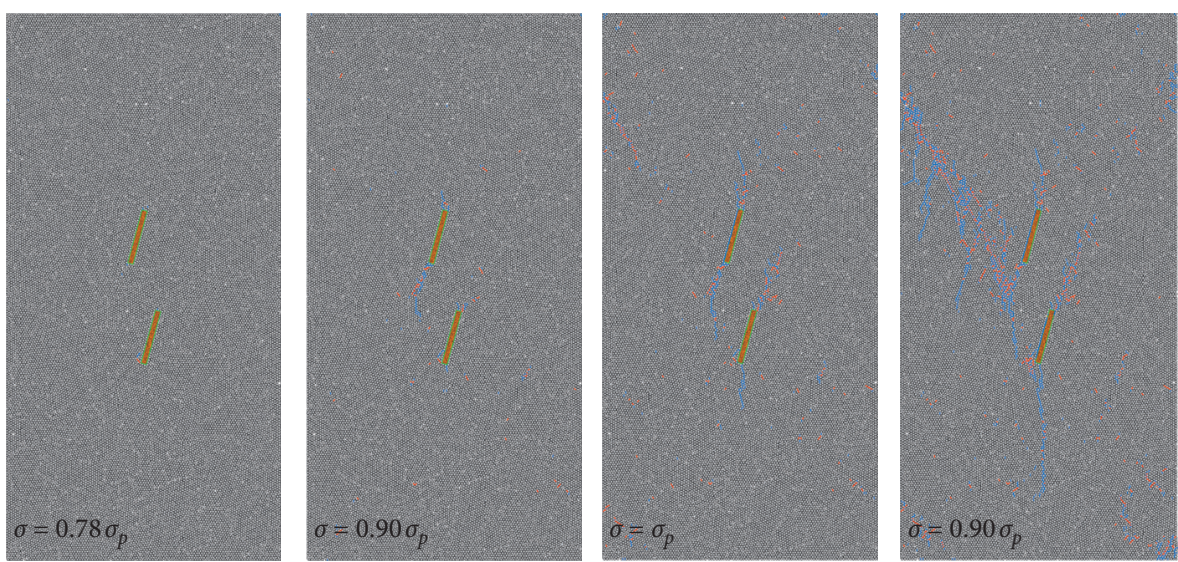

(c)

FIGURE 10: Crack development process of samples containing infilled flaws with the same $\alpha$ of $75^{\circ}$ and different $\beta$ of $60^{\circ}$, $90^{\circ}$, and $120^{\circ}$ (blue cracks represent tensile cracks and red cracks represent shear cracks). (a) $\alpha=75^{\circ}$ and $\beta=60^{\circ}$, (b) $\alpha=75^{\circ}$ and $\beta=90^{\circ}$, (c) $\alpha=75^{\circ}$ and $\beta=120^{\circ}$. 


\begin{tabular}{|c|c|c|}
\hline & Initial loading stage & Postpeak stage \\
\hline $\begin{array}{l}\beta=60^{\circ} \\
\alpha=75^{\circ}\end{array}$ & $\begin{array}{c}\text { Contact force_mag } \\
\text { Contacts }(80305) \\
3.7729 E+04 \\
3.7500 E+04 \\
3.5000 E+04 \\
3.2500 E+04 \\
3.0000 E+04 \\
2.7500 E+04 \\
2.5000 E+04 \\
2.2500 E+04 \\
2.0000 E+04 \\
1.7500 E+03 \\
1.5000 E+04 \\
1.2500 E+04 \\
1.0000 E+04 \\
7.5000 E+03 \\
5.0000 E+03 \\
2.5000 E+03 \\
4.3246 E-02\end{array}$ & $\begin{array}{c}\text { Contact force_mag } \\
\text { Contacts }(80281) \\
4.7098 E+04 \\
4.5000 E+04 \\
4.2500 E+04 \\
4.0000 E+04 \\
3.7500 E+04 \\
3.5000 E+04 \\
3.2500 E+04 \\
3.0000 E+04 \\
2.7500 E+04 \\
2.5000 E+03 \\
2.2500 E+04 \\
2.0000 E+04 \\
1.7500 E+04 \\
1.5000 E+04 \\
1.2500 E+04 \\
1.0000 E+04 \\
7.5000 E+03 \\
5.0000 E+03 \\
2.5000 E+03 \\
1.6064 E-02\end{array}$ \\
\hline $\begin{array}{l}\beta=90^{\circ} \\
\alpha=75^{\circ}\end{array}$ & 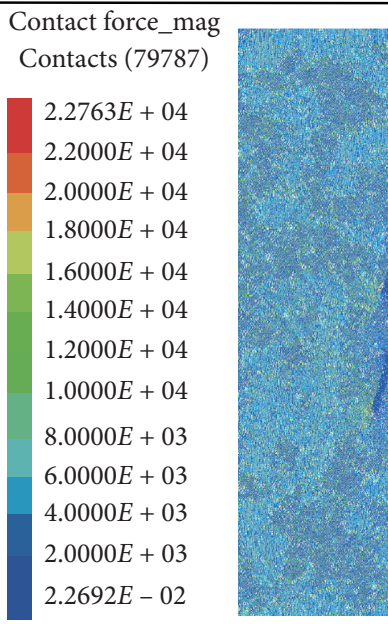 & 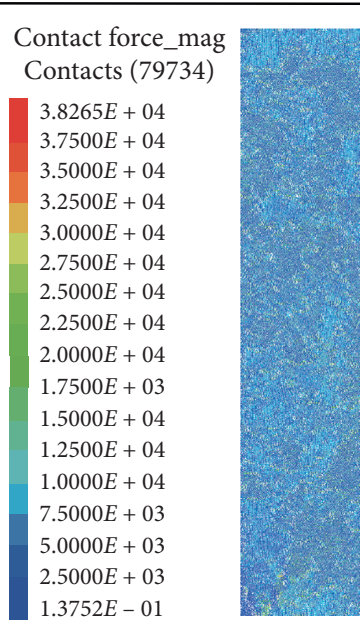 \\
\hline $\begin{array}{c}\beta=120^{\circ} \\
\alpha=75^{\circ}\end{array}$ & 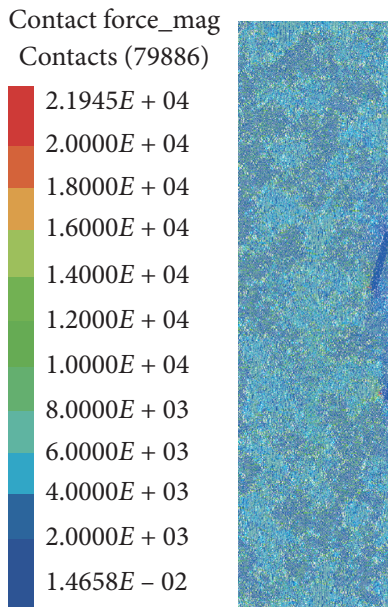 & 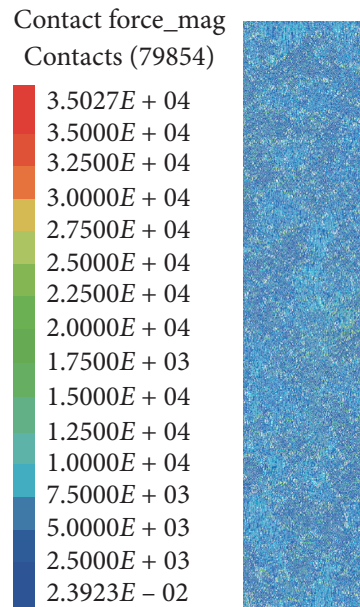 \\
\hline
\end{tabular}

Figure 11: Contact force of samples containing infilled flaws with the same $\alpha$ of $75^{\circ}$ and different $\beta$ of $60^{\circ}, 90^{\circ}$, and $120^{\circ}$. 
TABLE 4: Mechanical properties of samples with two parallel infilled flaws having different $\alpha$ and $\beta$.

\begin{tabular}{|c|c|c|c|c|c|c|}
\hline \multirow[b]{2}{*}{ Mechanical properties } & \multicolumn{3}{|c|}{ Infilled flaws with different $\alpha$} & \multicolumn{3}{|c|}{ Infilled flaws with different $\beta$} \\
\hline & $\begin{array}{c}\beta=90^{\circ} \\
\alpha=0^{\circ}\end{array}$ & $\begin{array}{l}\beta=90^{\circ} \\
\alpha=45^{\circ}\end{array}$ & $\begin{array}{l}\beta=90^{\circ} \\
\alpha=90^{\circ}\end{array}$ & $\begin{array}{l}\beta=60^{\circ} \\
\alpha=75^{\circ}\end{array}$ & $\begin{array}{l}\beta=90^{\circ} \\
\alpha=75^{\circ}\end{array}$ & $\begin{array}{c}\beta=120^{\circ} \\
\alpha=75^{\circ}\end{array}$ \\
\hline Uniaxial compressive strength $(\mathrm{MPa})$ & 23.3 & 28.3 & 33.3 & 33.0 & 33.7 & 34.5 \\
\hline Initiation stress $(\mathrm{MPa})$ & 14.5 & 16.7 & 29.0 & 29.5 & 27.8 & 27.0 \\
\hline Elastic modulus (GPa) & 22.2 & 22.7 & 24.1 & 23.9 & 24.0 & 24.0 \\
\hline Poisson's ratio & 0.20 & 0.22 & 0.20 & 0.21 & 0.21 & 0.21 \\
\hline
\end{tabular}
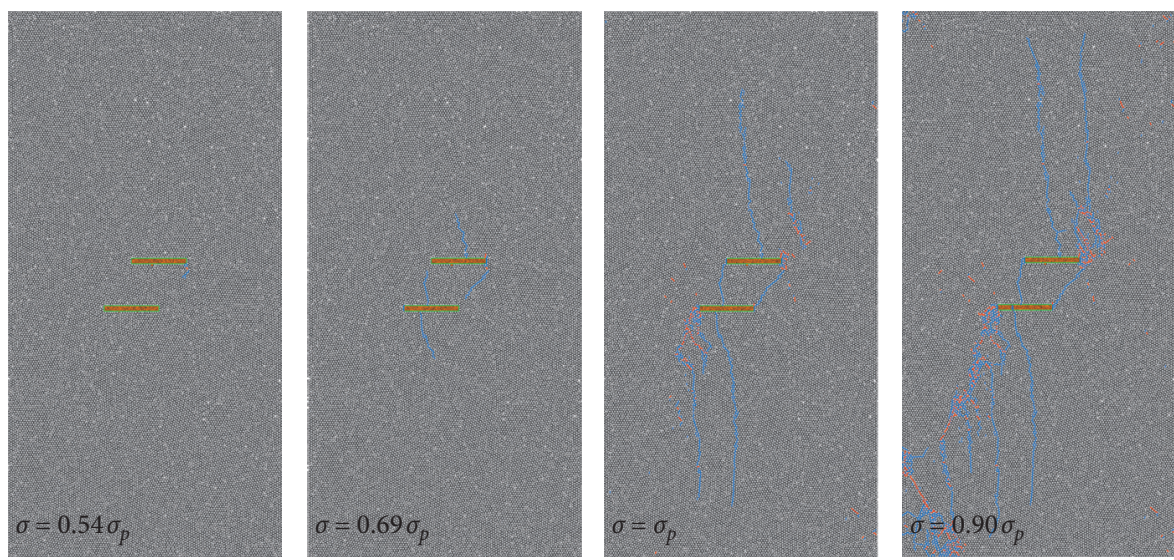

(a)
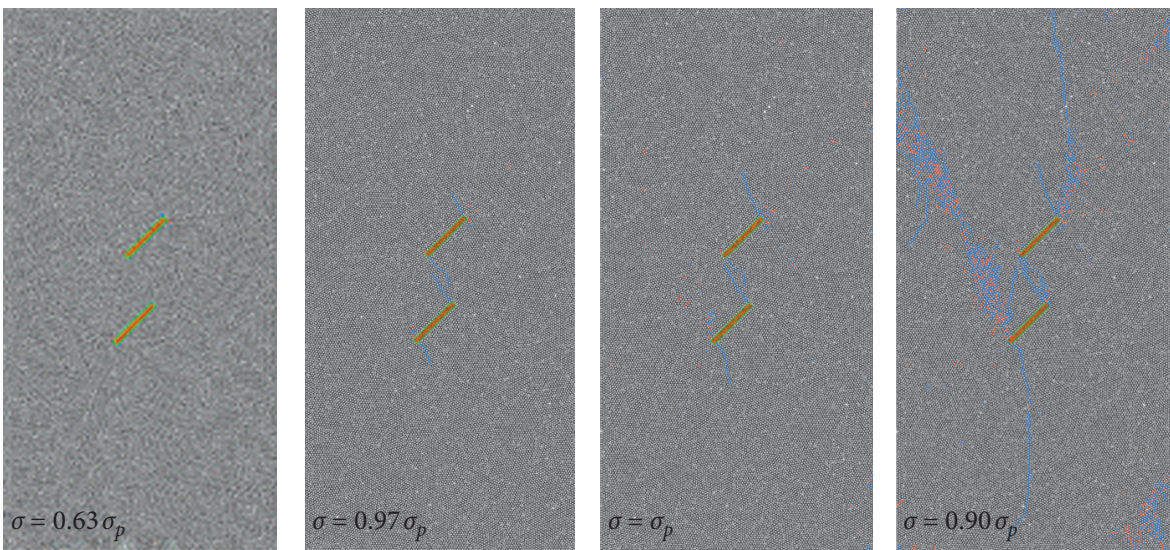

(b)
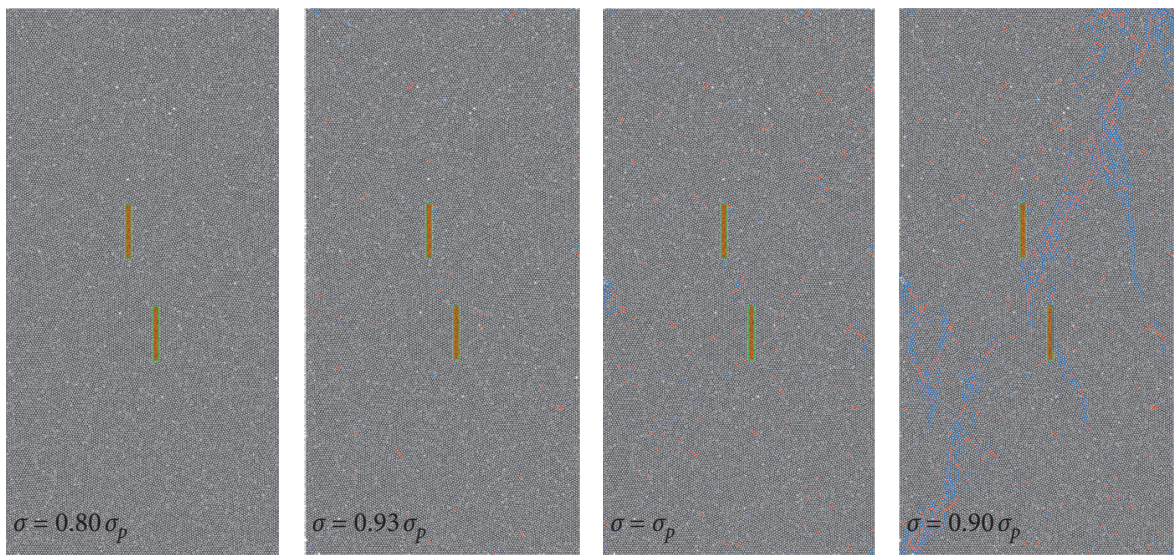

(c)

Figure 12: Crack development process of samples containing infilled flaws with the same $\beta$ of $120^{\circ}$ and different $\alpha$ of $0^{\circ}, 45^{\circ}$, and $90^{\circ}$ (blue cracks represent tensile cracks and red cracks represent shear cracks). (a) $\alpha=0^{\circ}$ and $\beta=120^{\circ}$, (b) $\alpha=45^{\circ}$ and $\beta=120^{\circ}$, (c) $\alpha=90^{\circ}$ and $\beta=120^{\circ}$. 


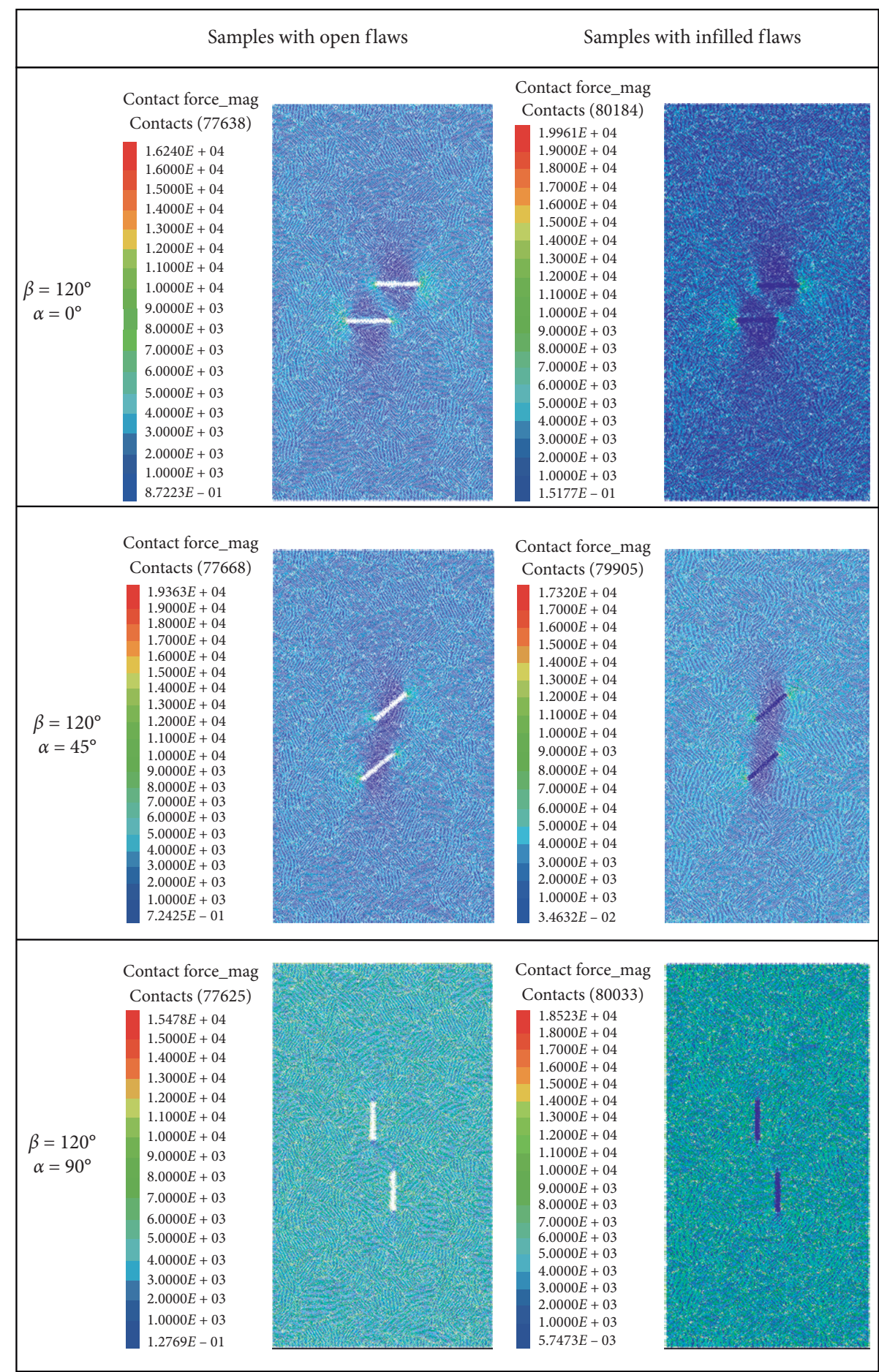

FIGURE 13: Contact force of samples containing open and infilled flaws with $\beta$ of $120^{\circ}$ and $\alpha$ of $0^{\circ}, 45^{\circ}$, and $90^{\circ}$ when the loading stress reaches the crack initiation stress. 


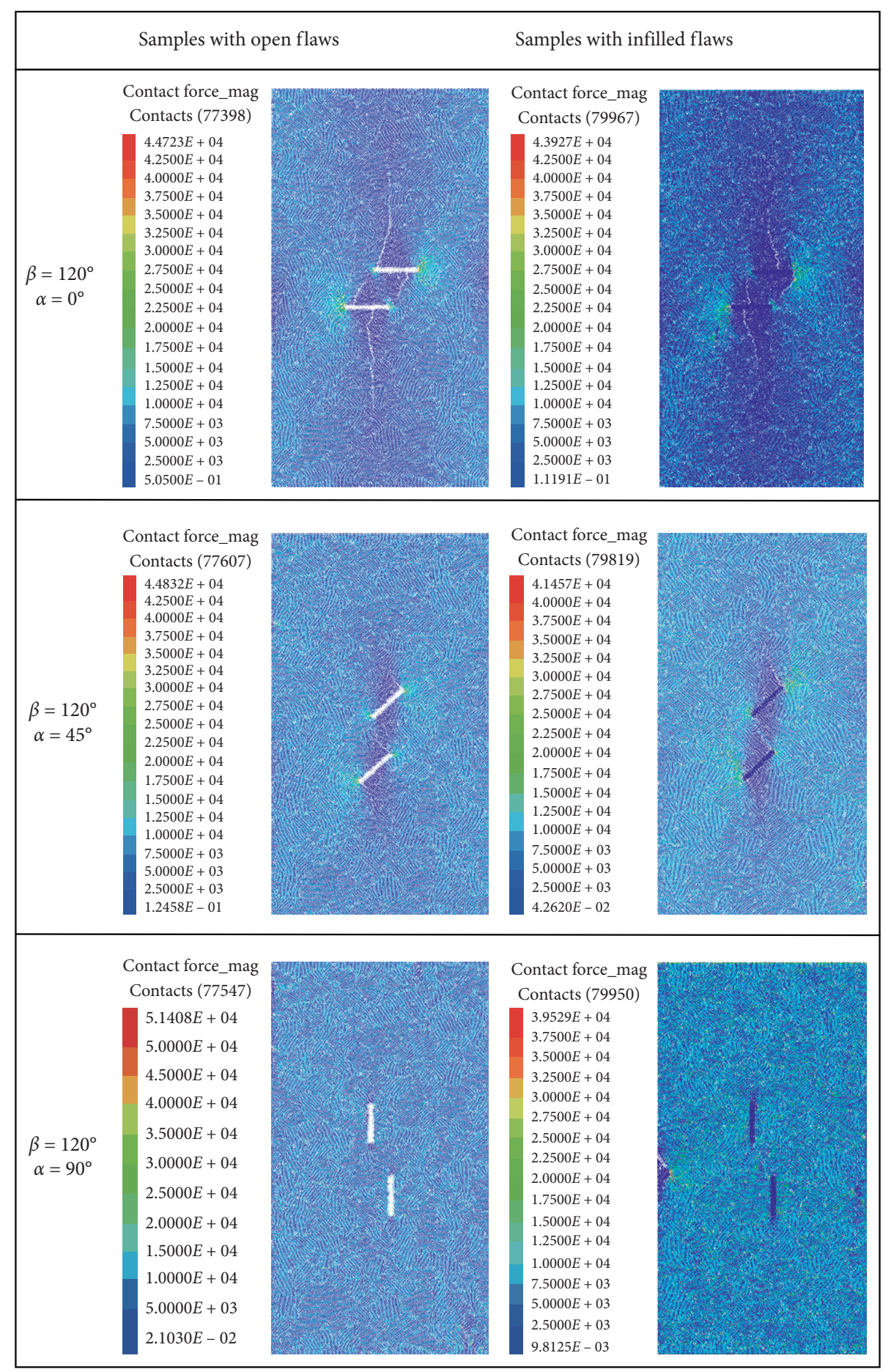

FIGURE 14: Contact force of samples containing open and infilled flaws with $\beta$ of $120^{\circ}$ and $\alpha$ of $0^{\circ}, 45^{\circ}$, and $90^{\circ}$ when the loading stress reaches the peak stress. 
TABLe 5: Mechanical properties of specimens with two parallel open flaws or infilled flaws.

\begin{tabular}{lccccc}
\hline & \multicolumn{3}{c}{ Specimens with open flaws } & \multicolumn{2}{c}{ Specimens with infilled flaws } \\
Mechanical properties & $\beta=120^{\circ}$ & $\beta=120^{\circ}$ & $\beta=120^{\circ}$ & $\begin{array}{c}\beta=120^{\circ} \\
\alpha=0^{\circ}\end{array}$ & $\begin{array}{c}\beta=120^{\circ} \\
\alpha=45^{\circ}\end{array}$ \\
& $\alpha=0^{\circ}$ & $\alpha=45^{\circ}$ & $\alpha=90^{\circ}$ & $\begin{array}{c}\beta=120^{\circ} \\
\alpha=90^{\circ}\end{array}$ \\
\hline Uniaxial compressive strength (MPa) & 23.6 & 28.1 & 37.2 & 24.7 & 30.6 \\
Initiation stress (MPa) & 12.8 & 17.9 & 29.7 & 13.4 & 37.3 \\
Elastic modulus (GPa) & 18.0 & 23.1 & 24.1 & 18.4 & 23.2 \\
Poisson's ratio & 0.21 & 0.21 & 0.20 & 0.26 & 29.9 \\
\hline
\end{tabular}

\section{Conclusions}

To study the effect of grouting on fracturing behavior and mechanical property of rock masses, numerical tests were carried out on rock specimens with two parallel flaws which were open or infilled. Crack development process, contact force, initiation stress, peak stress, elastic modulus, and Poisson's ratio were observed and analyzed. The main conclusions are as follows:

(1) The smooth joint model was proved to be appropriate to simulate the interface between grouting material and rock material. By using the smooth joint model, shear cracks that occurred at the interface were successfully simulated. It may provide some help for the following researchers to simulate the interface between grouting material and rock material.

(2) Grouting can reduce the tensile force of the particles, suppress the generation of tensile cracks, and improve the initiation stress of the sample. The tensile force of particles of samples containing infilled flaws is smaller than those containing open flaws, tensile crack is not easy to emanate in the samples with infilled flaws, and the peak strength of the sample is improved.

(3) As the increases of flaw inclination angle, the ratio of crack initiation stress to peak stress increases. It is more difficult for cracks to initiate as the flaw inclination angle increases.

(4) As the bridge inclination angle increases, the tensile force decreases, the contact is not easy to break, and the sample is not easy to be damaged. The bridge inclination angle has a certain influence on the strength of samples with infilled flaws.

(5) Crack development process includes the crack initiation position and propagation pattern was affected by both flaw inclination angle and bridge inclination angle.

\section{Data Availability}

The data used to support the findings of this study are available from the corresponding author upon request.

\section{Conflicts of Interest}

The authors declare that there are no conflicts of interest regarding the publication of this paper.

\section{Acknowledgments}

The authors gratefully acknowledge the financial support provided by National Natural Science Foundation of China (nos. 41672258, 42007256, and 41102162) and the Fundamental Research Funds for the Central Universities (B210201002).

\section{References}

[1] L. N. Y. Wong and H. H. Einstein, "Systematic evaluation of cracking behavior in specimens containing single flaws under uniaxial compression," International Journal of Rock Mechanics and Mining Sciences, vol. 46, no. 2, pp. 239-249, 2009.

[2] S.-Q. Yang and H.-W. Jing, "Strength failure and crack coalescence behavior of brittle sandstone samples containing a single fissure under uniaxial compression," International Journal of Fracture, vol. 168, no. 2, pp. 227-250, 2011.

[3] T. M. Cebasek and T. Fruehwirt, "Investigation of creep behaviours of gypsum specimens with flaws under different uniaxial loads," International Journal of Rock Mechanics and Geotechnical Engineering, vol. 10, no. 1, pp. 151-163, 2017.

[4] X.-P. Zhou, J.-Z. Zhang, and L. N. Y. Wong, "Experimental study on the growth, coalescence and wrapping behaviors of 3D cross-embedded flaws under uniaxial compression," Rock Mechanics and Rock Engineering, vol. 51, no. 5, pp. 1379-1400, 2018.

[5] H. Lin, H. Yang, Y. Wang, Y. Zhao, and R. Cao, "Determination of the stress field and crack initiation angle of an open flaw tip under uniaxial compression," Theoretical and Applied Fracture Mechanics, vol. 104, Article ID 102358, 2019.

[6] R. Xu, "Influence of flaw inclination angle on cracking behavior of rock-like materials under uniaxial compression," Advances in Material Science and Engineering, vol. 2019, Article ID 694258, 10 pages, 2019.

[7] Y. Wang, J. Q. Han, and C. H. Li, "Acoustic emission and CT investigation on fracture evolution of granite containing two flaws subjected to freeze-thaw and cyclic uniaxial increasingamplitude loading conditions," Construction Building and Materials, vol. 260, Article ID 119769, 2020.

[8] A. Bobet and H. H. Einstein, "Fracture coalescence in rocktype materials under uniaxial and biaxial compression," International Journal of Rock Mechanics and Mining Sciences, vol. 35, no. 7, pp. 863-888, 1998.

[9] C. H. Park and A. Bobet, "Crack coalescence in specimens with open and closed flaws: a comparison," International Journal of Rock Mechanics and Mining Sciences, vol. 46, no. 5, pp. 819-829, 2009.

[10] D. Huang, D. Gu, C. Yang, R. Huang, and G. Fu, "Investigation on mechanical behaviors of sandstone with two preexisting flaws under triaxial compression," Rock Mechanics and Rock Engineering, vol. 49, no. 2, pp. 375-399, 2016. 
[11] J. Duriez, L. Scholtès, and F.-V. Donzé, "Micromechanics of wing crack propagation for different flaw properties," Engineering Fracture Mechanics, vol. 153, p. 378, 2016.

[12] C. Zhang, Y. Wang, and T. Jiang, "The propagation mechanism of an oblique straight crack in a rock sample and the effect of osmotic pressure under in-plane biaxial compression," Arabian Journal of Geosciences, vol. 13, p. 736, 2020.

[13] H. Le, S. Sun, P. H. S. W. Kulatilake, and J. Wei, "Effect of grout on mechanical properties and cracking behavior of rock-like specimens containing single flaw under uniaxial compression," International Journal of Geomechanics, vol. 18, no. 10, 2018.

[14] S. Miao, P.-Z. Pan, Z. Wu, S. Li, and S. Zhao, "Fracture analysis of sandstone with a single filled flaw under uniaxial compression," Engineering Fracture Mechanics, vol. 204, p. 319, 2018.

[15] Y. Zhao, L. Zhang, F. Asce et al., "Experimental study on shear behavior and a revised shear strength model for infilled rock joints," International Journal of Geomechanics, vol. 20, 2020.

[16] J. Yoon, "Application of experimental design and optimization to PFC model calibration in uniaxial compression simulation," International Journal of Rock Mechanics and Mining Sciences, vol. 44, no. 6, pp. 871-889, 2007.

[17] J. De Bono, G. Mcdowell, and D. Wanatowski, "Discrete element modelling of a flexible membrane for triaxial testing of granular material at high pressures," Géotechnique Letters, vol. 2, no. 4, pp. 199-203, 2012.

[18] X.-P. Zhang and L. N. Y. Wong, "Crack initiation, propagation and coalescence in rock-like material containing two flaws: a numerical study based on bonded-particle model approach," Rock Mechanics and Rock Engineering, vol. 46, no. 5, pp. 1001-1021, 2013.

[19] D. O. Potyondy, "The bonded-particle model as a tool for rock mechanics research and application: current trends and future directions," Geosystem Engineering, vol. 18, no. 1, pp. 1-28, 2015.

[20] X. X. Yang, P. H. S. W. Kulatilake, X. Chen, H. W. Jing, and S. Q. Yang, "Particle flow modeling of rock blocks with nonpersistent open joints under uniaxial compression," International Journal of Geomechanics, vol. 16, no. 6, Article ID 04016020, 2016.

[21] J. Gong and J. Liu, "Mechanical transitional behavior of binary mixtures via DEM: effect of differences in contact-type friction coefficients," Computers and Geotechnics, vol. 85, pp. 114,2017

[22] X. Fan, K. Li, H. Lai, Q. Zhao, and Z. Sun, "Experimental and numerical study of the failure behavior of intermittent rock joints subjected to direct shear load," Advances in Civil Engineering, vol. 2018, Article ID 4294501, 19 pages, 2018.

[23] G. Liu, J. Peng, Z. Zhang, Z. Wang, and Y. Yang, "Numerical investigation of fluid-driven crack propagation and coalescence in granite specimen with two pre-existing flaws," Journal of Natural Gas Science and Engineering, vol. 75, 2020.

[24] D. O. Potyondy and P. A. Cundall, "A bonded-particle model for rock," International Journal of Rock Mechanics and Mining Sciences, vol. 41, no. 8, pp. 1329-1364, 2004.

[25] H. Lee and S. Jeon, "An experimental and numerical study of fracture coalescence in pre-cracked specimens under uniaxial compression," International Journal of Solids and Structures, vol. 48, no. 6, pp. 979-999, 2011.

[26] Z. Zhao and D. Zhou, "Mechanical properties and failure modes of rock samples with grout-infilled flaws: a particle mechanics modeling," Journal of Natural Gas Science and Engineering, vol. 34, pp. 702-715, 2016.
[27] M. H. Mehranpour and P. H. S. W. Kulatilake, "Improvements for the smooth joint contact model of the particle flow code and its applications," Computers and Geotechnics, vol. 87, pp. 163-177, 2017. 